\title{
Possibly Related to Intervention
}

National Cancer Institute

\section{Source}

National Cancer Institute. Possibly Related to Intervention. NCI Thesaurus. Code C53258.

A characteristic indicating that an adverse event may be related to the medical intervention. According to WHO causality assessment criteria of suspected adverse reactions it is applicable to a clinical event, including laboratory test abnormality, with a reasonable time sequence to administration of the drug, but which could also be explained by concurrent disease or other drugs or chemicals. Information on drug withdrawal may be lacking or unclear. 